\title{
Functional hyposplenism in alcoholic liver disease: a toxic effect of alcohol?
}

\author{
A F Muller, P J Toghill
}

\begin{abstract}
Functional hyposplenism, seen in some patients with alcoholic liver disease, may contribute to the increased susceptibility to infections. As hyposplenism does not complicate non-alcohol related chronic liver disease, it is probably secondary to a toxic effect of alcohol. Over a two year period the case notes of 82 patients with alcoholic liver disease, whose splenic function had been assessed by the counting of pitted erythrocytes using differential interference microscopy, were reviewed to monitor mortality and the effects of hyposplenism. Thirteen patients (seven with hyposplenism) had serial measurements of pitted erythrocyte count made to assess the effect of abstinence from alcohol on splenic function. Thirty one of the 82 alcoholic patients had pitted erythrocyte counts greater than $2 \%$. Eighteen of $82(16 \%)$ patients died over the two years and 11 of these had been unable to stop drinking. Only one patient died of sepsis. Five patients $(6 \%)$ had pitted erythrocyte counts comparable with those in splenectomised patients. In 12 of 13 patients who had abstained from alcohol for two months, the pitted erythrocyte count fell from a median of 3 to $1 \cdot 3 \%$ (mean: $8 \cdot 1$ to $2 \cdot 6 \%$. $p=0 \cdot 01$ ). The pitted red cell count in two patients increased. One had abstained, the other had continued to drink heavily. Short term mortality in alcoholics is high, particularly if they continue to drink heavily. Only a few of these deaths are secondary to infection. Splenic function, as assessed by these methods, improves in most patients with abstinence, suggesting that the functional hyposplenism may be a result of a direct toxic effect of alcohol on the spleen. (Gut 1994; 35: 679-682)
\end{abstract}

The haematological abnormalities associated with alcoholic liver disease are complex. ${ }^{1}$ We often see evidence of 'haematological hypersplenism' (that is anaemia, leukopenia, and thrombocytopenia) but some alcoholics have functional hyposplenism (that is reduced splenic function in the presence of a spleen) as measured by an increased percentage of erythrocytes with 'pits' or surface indentations when viewed under differential interference contrast microscopy. ${ }^{2}$ Under the electron microscope these pits are seen to be intracellular vacuoles containing intracellular debris. ${ }^{3}$

The effects of hyposplenism in patients with alcoholic liver disease, similar to those in splenectomised patients, may contribute to the increased risk of infection. ${ }^{2}$ The explanation for the hyposplenism is unclear, but it seemed that current heavy drinkers were most at risk as reformed alcoholics had normal pitted erythrocyte counts. Although there has been one description of hyposplenism related to immune chronic active hepatitis, ${ }^{+}$we have not confirmed this in patients with chronic liver disease such as primary biliary cirrhosis or chronic active hepatitis. ${ }^{5}$ This all suggests that the hyposplenism may be secondary to a toxic effect of alcohol.

In health, less than $2 \%$ of erythrocytes contain pits, ${ }^{26}$ whereas in splenectomised patients up to $50 \%$ of cells show one or more pits. This, therefore, gives an assessment of splenic function (albeit an indirect one) which correlates with the more complex methods such as the clearance of isotopically labelled heat damaged erythrocytes. ${ }^{78}$

Over the two years 1991-92, the case notes of all patients in whom splenic function had been assessed by measurements of pitted erythrocyte counts were reviewed to assess the following: mortality in relation to continued drinking and the presence of hyposplenism; severity of functional hyposplenism compared with a group of splenectomised patients; and the effect of abstinence from alcohol on splenic function.

\section{Methods}

\section{PATIENTS}

Over an 18 month period, 82 patients of mean age 51 years (range 27-78 years, 57 men, 25 women) with alcoholic liver disease were studied. Patients were hospital inpatients and outpatients, with 15 additional subjects recruited from an alcohol withdrawal centre. All had a longstanding history of alcohol abuse, with significantly abnormal liver function tests and ultrasound or isotopic evidence of liver disease. At the time of recruitment into the study, a full history and clinical examination was performed together with specific questioning about previous and current infections. All patients with ascites had a diagnostic paracentesis to exclude bacterial peritonitis and those with fever or encephalopathy had blood and urine cultures and a chest $x$ ray.

The case notes of all subjects were reviewed to determine outcome and confirm histology. Thirty had had liver biopsies, which showed cirrhosis in 24 and alcoholic hepatitis in three. The histology in three patients included a combination of cholestasis, steatosis, lipogranulomatosis, and arachnoid fibrosis. None of the alcoholics studied had other diseases in which hyposplenism has previously been reported. ${ }^{69}$

In 13 patients, assessment of pitted erythrocyte count was repeated after a minimum

interval of two months. Seven of this group had
Department of Medicin A F Muller

Dr A F Muller, c/o Secretary to Dr R G Love, Nottingham City Hospital, Hucknall Road, gham NGS $1 P$.

Accepted for publication 13 August 1993 
significant hyposplenism, as indicated by high pitted erythrocyte counts. All but one of these had abstained from alcohol over this period and this assessment was corroborated by close relatives and negative blood alcohol concentrations, together with an improvement in the liver function tests. Some patients identified as having hyposplenism (whom we would like to have reassessed) failed to attend for repeat blood sampling. Reasons for this included failure to attend follow up clinics despite written requests, inability to attend hospital on account of the distance involved (some patients at the alcohol withdrawal centre came from more than 100 miles away), and death of the patient.

A comparison of the severity of the hyposplenism of alcoholic liver disease was made with 12 non-alcoholic patients who had undergone splenectomy (for trauma or myeloproliferative disease) from three months to 10 years previously. The mean age was 59 years (range 21-76 years).

All subjects gave informed consent.

\section{ASSESSMENT OF SPLENIC FUNCTION}

All patients had had a full blood count and film looking for evidence of both 'haematological hypersplenism' (anaemia, leukopenia, and thrombocytopenia) and severe hyposplenism (Howell-Jolly bodies, acanthocytes, and target cells).

Splenic function was assessed by the method described by Corazza et al. ${ }^{8}$ A single drop of an erythrocyte preparation (taken from one drop of blood to which was added $0.5 \mathrm{ml}$ of $3 \%$ glutaraldehyde at $\mathrm{pH} 7 \cdot 4$ in a plastic tube and

TABLE I Demography of the 13 patients who died during the period of study. One of the patients with hyposplenism died of septicaemia (no 6). Patient 1 , studied several months apart, increased the pitted red cell count with continued drinking

\begin{tabular}{|c|c|c|c|c|c|c|}
\hline $\begin{array}{l}\text { Patient } \\
\text { no }\end{array}$ & $\begin{array}{l}\text { Age } \\
(y)\end{array}$ & Sex & $\begin{array}{l}\text { Pitted } \\
\text { erythrocyte } \\
\text { count }(\%)\end{array}$ & Alcohol & Histology & Cause of death \\
\hline 1 & 47 & $\mathbf{F}$ & $5 \cdot 2,7 \cdot 2$ & $\begin{array}{c}\text { Continued } \\
\text { drinking }\end{array}$ & Cirrhosis & Variceal bleed \\
\hline 2 & 41 & $M$ & 0.9 & Drinking & - & Liver failure \\
\hline 3 & 78 & $\mathbf{M}$ & $0 \cdot 8$ & Abstinent & Cirrhosis & Liver failure \\
\hline 4 & 67 & $\mathbf{M}$ & $0 \cdot 4$ & Abstinent & Cirrhosis & Hepatoma \\
\hline 5 & 51 & $\mathrm{M}$ & $1 \cdot 0$ & Drinking & - & Liver failure \\
\hline 6 & 61 & $\mathbf{F}$ & $6 \cdot 1$ & Drinking & Alcoholic hepatitis & Pneumococcal septicaemia \\
\hline 7 & 61 & $M$ & $5 \cdot 1$ & Drinking & Cirrhosis & Recurrent Hodgkins disease \\
\hline 8 & 34 & M & $1 \cdot 2$ & Drinking & - & Delerium tremens \\
\hline 9 & 35 & $\mathbf{F}$ & 3.4 & Drinking & - & House fire \\
\hline 10 & 58 & $\mathbf{M}$ & $4 \cdot 1$ & Drinking & Cirrhosis & Fulminant pancreatitis \\
\hline 11 & 56 & M & $1 \cdot 3$ & Drinking & Cirrhosis & $\mathrm{DIC}^{\star}$, hypothermia \\
\hline 12 & 67 & $\mathbf{M}$ & 1.9 & Drinking & Cirrhosis & Carcinoma of pancreas \\
\hline 13 & 65 & $\mathbf{F}$ & 6.9 & Drinking & Cirrhosis & Liver failure \\
\hline
\end{tabular}

^DIC= disseminated intravascular coagulation mixed) was examined under oil emersion using a Zeiss Axioskop microscope fitted for differential interference contrast microscopy at a magnification of 1000 . For each sample, 1000 erythrocytes were counted and the percentage of cells with one or more pits noted. Corazza et al, ${ }^{8}$ in their original study, counted 2000 cells. We have shown that counting 1000 cells reduces the time to analyse each sample without compromising the accuracy. This reproducibility study has been published separately. ${ }^{5}$

\section{STATISTICAL ANALYSIS}

Wilcoxon's signed rank test was used to compare pitted erythrocyte counts in the alcoholics whilst still drinking with the same patients who had avoided alcohol completely for a minimum of 2 months.

\section{Results}

Over the 24 month period of follow up, 13 of the 82 patients (16\%) died (Table I). Most of these had continued to drink heavily. The majority of deaths resulted from end stage liver disease, but one patient died from a fulminant pneumococcal septicaemia. This patient, together with four others in this group, had raised pitted erythrocyte counts.

The presence of target cells on the blood film was common but only one patient was reported to have Howell-Jolly bodies (patient 7, Table II).

Thirty one of 82 alcoholic patients were found to have pitted erythrocyte counts greater than $2 \%$. Of these, five $(6 \%)$ had significant hyposplenism (counts $>10 \%$ ). Figure 1 shows a comparison between the alcoholics and splenectomised patients. The median count in the alcoholics was $1.7 \%$, with a range from 0.4 $34 \cdot 8 \%$. This compared with the splenectomised patients with a median count of 35.3 (range 9.8 $53) \%$. Some of the alcohol group had pitted erythrocyte counts comparable with the splenectomised group.

Figure 2 shows the results of pitted erythrocyte counts in 12 patients who were studied while drinking heavily and subsequently after a minimum of two months abstinence from alcohol. In all but one patient, pit counts fell towards normal on repeat testing (median 3\% drinking, $1.3 \%$ abstinent; mean drinking $8 \cdot 1 \%$ to abstinent $2 \cdot 6 \%, p=0 \cdot 01$ ). Evidence that this patient (a 72 year old woman, patient 7 , Table II) had stopped drinking came from carers and close relatives

TABLE II Haematochemical parameters of the patients with the most severe hyposplenism as judged by pitted erythrocyte counts. Test $1=$ original samples; test $2=$ those measured at least 2 months following the first sample. Only patient 1 had continued to drink heavily

\begin{tabular}{|c|c|c|c|c|c|c|c|c|c|c|c|c|c|c|c|c|c|}
\hline \multirow[b]{2}{*}{$\begin{array}{l}\text { Patient } \\
\text { no }\end{array}$} & \multirow[b]{2}{*}{$\begin{array}{l}\text { Age } \\
(y)\end{array}$} & \multirow[b]{2}{*}{ Sex } & \multicolumn{7}{|l|}{ Test 1} & \multicolumn{7}{|l|}{ Test 2} & \multirow[b]{2}{*}{ Histology/comments } \\
\hline & & & $\begin{array}{l}\text { Pit } \\
\text { count } \\
(\%)\end{array}$ & $G G T$ & Bil & $H b$ & $M C V$ & $W C C$ & Plts & $\begin{array}{l}\text { Pit } \\
\text { count } \\
(\%)\end{array}$ & $G G T$ & Bil & $H b$ & $M C V$ & $W C C$ & Plts & \\
\hline $\begin{array}{l}1 \\
2 \\
3 \\
4 \\
5 \\
6\end{array}$ & $\begin{array}{l}47 \\
49 \\
61 \\
42 \\
34 \\
43\end{array}$ & $\begin{array}{l}\mathrm{F} \\
\mathbf{M} \\
\mathrm{M} \\
\mathrm{M} \\
\mathrm{M} \\
\mathrm{M}\end{array}$ & $\begin{array}{c}5 \cdot 2 \\
4 \cdot 9 \\
15 \\
21 \cdot 6 \\
9 \cdot 2 \\
34 \cdot 8\end{array}$ & $\begin{array}{r}279 \\
272 \\
124 \\
3971 \\
2367 \\
5240\end{array}$ & $\begin{array}{r}360 \\
91 \\
12 \\
41 \\
259 \\
191\end{array}$ & $\begin{array}{r}9 \cdot 3 \\
13.1 \\
11.8 \\
17.8 \\
11.8 \\
10.2\end{array}$ & $\begin{array}{l}109 \\
103 \\
102 \\
106 \\
109 \\
100\end{array}$ & $\begin{array}{r}13 \cdot 5 \\
10 \cdot 9 \\
6 \cdot 6 \\
8 \cdot 3 \\
16 \cdot 3 \\
5 \cdot 3\end{array}$ & $\begin{array}{r}110 \\
142 \\
92 \\
175 \\
120 \\
120\end{array}$ & $\begin{array}{l}7 \cdot 2 \\
0 \cdot 7 \\
7 \cdot 8 \\
1.9 \\
3 \cdot 0 \\
2 \cdot 3\end{array}$ & $\begin{array}{r}469 \\
98 \\
69 \\
451 \\
282 \\
62\end{array}$ & $\begin{array}{r}70 \\
11 \\
8 \\
9 \\
28 \\
11\end{array}$ & $\begin{array}{r}11.6 \\
9.9 \\
14.6 \\
15.7 \\
13.6 \\
15.8\end{array}$ & $\begin{array}{r}109 \\
101 \\
98 \\
100 \\
101 \\
90\end{array}$ & $\begin{array}{l}8 \cdot 4 \\
5 \cdot 6 \\
4.5 \\
9 \cdot 2 \\
6.8 \\
4.0\end{array}$ & $\begin{array}{l}180 \\
185 \\
136 \\
338 \\
140 \\
160\end{array}$ & $\begin{array}{l}\text { Cirrhosis; drinking } \\
\text { Cirrhosis } \\
\text { No biopsy } \\
\text { No biopsy } \\
\text { Steatosis, arachnoid fibrosis } \\
\text { Lipogranulomatosis } \\
\text { arachnoid fibrosis }\end{array}$ \\
\hline 7 & 73 & $\mathrm{~F}$ & $4 \cdot 0$ & 302 & 123 & $12 \cdot 8$ & 107 & $8 \cdot 9$ & 51 & $9 \cdot 3$ & 147 & 156 & $11 \cdot 3$ & 95 & $11 \cdot 1$ & 82 & No biopsy \\
\hline
\end{tabular}

GGT=gamma glutamyl transferase; $\mathrm{Bil}=$ bilirubin; $\mathrm{Hb}=$ haemoglobin; $\mathrm{MCV}=$ mean corpuscular volume; $\mathrm{WCC}=$ white cell count; $\mathrm{Plts}=$ platelets. 
Figure 1: Pitted erythrocyte counts in patients with alcoholic liver disease $(n=$ 82) compared with splenectomised patients $(n=$ 12). Some patients with alcoholic liver disease have severe hyposplenism comparable with patients who have had a splenectomy.

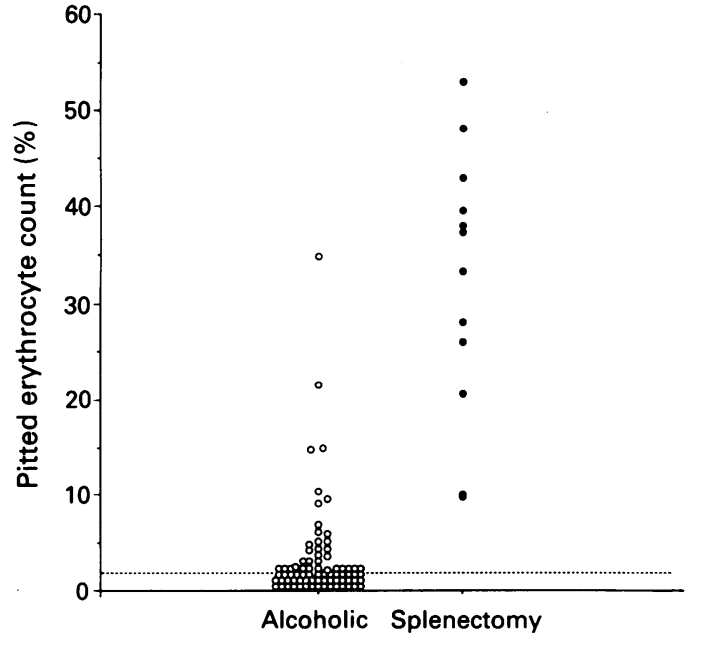

Patient group

together with serial negative blood alcohol concentrations. This patient's liver function tests failed to improve and she remained deeply jaundiced and at one stage required treatment for hepatic encephalopathy. This patient's blood film revealed Howell-Jolly bodies.

The haematological and biochemical parameters for those patients with significant hyposplenism are illustrated in Table II. Patient 1 , a 47 year old woman continued to drink heavily and died at home from a massive variceal haemorrhage. Her pitted erythrocyte count remained high on serial testing. We have previously reported that this patient developed a klebsiella urinary tract infection complicating her hyposplenism. ${ }^{2}$ In patients $2-6$, the fall in the pitted erythrocyte count with abstinence was associated with an improvement in the haematochemical parameters. Patients 5 and 6 , both jaundiced and with lipaemic serum, were the only two patients to have moderate polychromasia and anaemia on the blood film suggestive of haemolysis (Zieve's syndrome ${ }^{10}$ ). Although we did not specifically measure the reticulocyte count in our patients, no other patients had significant polychrornasia or features of haemolysis on the blood film.

Table II also indicates that hyposplenism was not confined to patients recognised to have cirrhosis. The liver histology in patients 5 and 6

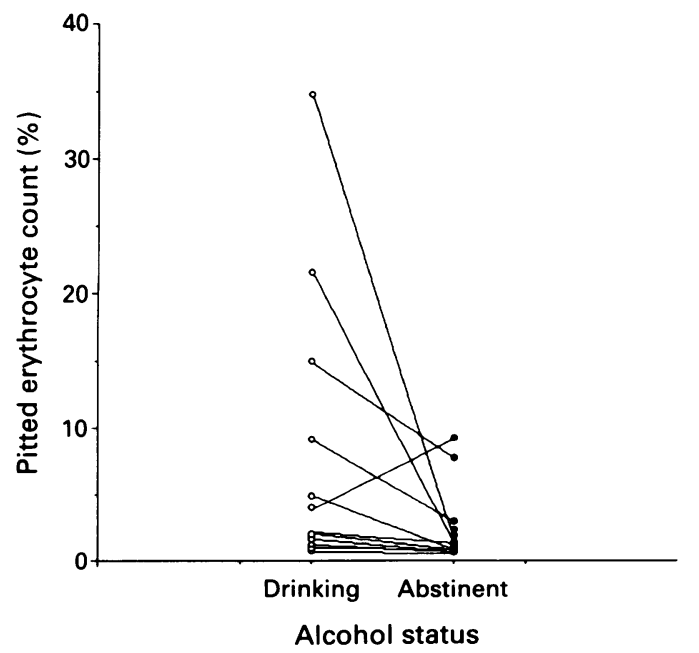

showed fatty infiltration together with some evidence of arachnoid fibrosis without apparent cirrhosis.

\section{Discussion}

The clarification of any new additional mechanism likely to worsen the susceptibility of the alcoholic to infection is of importance. While a high pitted erythrocyte count is only an indirect method of assessing splenic function, these results point to significant splenic hypofunction in alcoholics which may be reversible on abstinence.

Functional hyposplenism needs to be distinguished from the 'haematological hypersplenism' seen in many patients with chronic liver disease. Earlier reports of hyposplenism in patients with non-alcohol related liver disease ${ }^{4}$ have not been confirmed. ${ }^{5}$ This suggests that the hyposplenism of alcoholic liver disease is a toxic effect of alcohol.

This study has confirmed the well recognised increased mortality in patients with alcoholic liver disease, ${ }^{12}$ with most deaths resulting from the sequelae of end stage liver disease associated with continuing alcohol abuse rather than sepsis. Severe hyposplenism, comparable with that in splenectomised patients, can occur, and was not necessarily confined to patients with biopsy proved cirrhosis. It was found in patients with earlier histological features of alcohol abuse, including fatty liver.

Although lesser degrees of hyposplenism seem to be relatively common, six of 82 of this group of patients had pitted erythrocyte counts in the range found in splenectomised patients (Fig 1). The presence of functional hyposplenism, even when the pitted erythrocyte count is less than $10 \%$, remains significant as this group still seems to be at risk of increased risk of infection. ${ }^{2}$

The pitted cell counts in all but one of the patients (patient 7, Table II) in this study improved when they stopped drinking alcohol. In patient 7 , the pitted count increased and Howell-Jolly bodies appeared on the blood film. It may be that this patient, unknown to her close relatives, continued to drink alcohol although serial blood alcohol concentrations were always negative. She had also been hospitalised for several weeks before the second sample was taken because of the complications of her liver disease. If continued alcohol consumption was not responsible for the deterioration in splenic function, what other factors might have been responsible? Firstly, the functional hyposplenism in advanced alcoholic liver disease may not always be reversible. Secondly, the elderly are known to show a decline in splenic function with age. ${ }^{13}$ Alternatively, longstanding jaundice and hepatic encephalopathy/liver failure may have contributed to the hyposplenism. Patient 13 , who had a modest increase in the pitted red cell count (Table I) died of liver failure with deep jaundice from continued drinking. Nonetheless, we have not shown the presence of functional hyposplenism in patients with either chronic active hepatitis or primary biliary cirrhosis, a number of whom had prolonged and noticeable degrees of jaundice.
Figure 2: Pitted erythrocyte alcoholic liver disease ( 12) while still drinking heavily and after a minimum of at least two months without alcohol. In all but one patient with a high initial pitted red cell count, $(p=0.01)$. 
The finding of two patients with marked hyposplenism thought likely to have Zieve's syndrome is of importance as it has been suggested previously that in patients with a high percentage of immature erythrocytes, particularly reticulocytes, more membrane indentations or pits are present. ${ }^{14}$ Evidence has been put forward that in patients with a high reticulocyte count, an 'overload syndrome' 15 develops whereby there might be a backlog of new cells awaiting clearance and 'depitting' by the spleen. In contrast, other authors have found increased erythrocytes with pits in mature cells. ${ }^{16}$ We have examined the cells from the alcoholics under scanning and transmission electron microscopy together with spectroscopy and have found no difference in the composition of pits in both these and splenectomised patients (Muller, Self, Dinsdale, and Toghill, unpublished observations). We accept that alcohol may have a toxic effect on the bone marrow, producing effects on red cell membranes and changes in red cell morphology that might influence the interpretation of this test. We believe, nevertheless, that even in the two patients thought to have a degree of haemolysis, the raised pitted red cell count remains a surrogate marker for the presence of hyposplenism.

How alcohol causes hyposplenism is unclear. It has been shown that alcoholics have impaired reticuloendothelial phagocytic capacity, 1718 believed to be the result of a toxic effect of either alcohol or endotoxins on Kupffer cells. The reduced reticuloendothelial phagocytic capacity is unrelated to the presence of haemolysis. ${ }^{19}$ No studies have shown these effects to be reversible. It is believed that red cells are 'depitted' at the interendothelial slits when they enter the venous sinuses from the reticuloendothelial meshwork. As with Kupffer cell dysfunction, alcohol may result in a 'sick cell syndrome' that interferes with this process. Nutritional factors may be important in the hyposplenism as abstinence and drying out are often associated with generally better nutrition. There is a suggestion that nutritional factors may be relevant to the functional hyposplenism seen in patients on long term parenteral nutrition..$^{20}$

Alcoholics, especially those who continue to drink, have a high mortality. Significant hyposplenism comparable with that in splenectomised patients, occurs in some patients with alcoholic liver disease. This may contribute to their increased risk of infection and is not confined to patients with cirrhosis. In most patients, continued abstinence reverses the hyposplenism, although the elderly and patients with liver failure may fail to improve their splenic function despite stopping drinking.

1 Sherlock S. The haematology of liver disease. In: Diseases of the liver and biliary system. 8th Ed. Oxford: Blackwell Scientific, 1989: 49-69.

2 Muller AF, Toghill PJ. Splenic function in alcoholic liver disease. Gut 1992; 33: 1386-9.

3 Schnitzer B, Rucknagel DL, Spencer HH, Aikawa M. Erythrocytes: pits and vacuoles as seen with transmission and scanning electron microscopy. Science 1971; 173: 251-2.

4 Dhawan VM, Spencer RP, Sziklar JJ. Reversible functional asplenia in chronic aggressive hepatitis. $\mathcal{F}$ Nucl Med 1979; 20: $34-6$.

5 Markus HS, Muller AF, Toghill PJ. Splenic function, assessed by quantification of erythrocyte membrane pits, is normal in by quantification of erythrocyte membrane pits, is normal in
chronic active hepatitis and primary biliary cirrhosis. chronic active hepatitis and

6 Foster PN, Losowsky MS. Hyposplenism. In: Bowdler AJ, ed. The spleen - structure, function and clinical significance. London: Chapman and Hall, 1990; 232-59.

7 Marsh GW, Lewis SM, Szur L. The use of ${ }^{51}$ chromium labelled heat-damaged red cells to study splenic function. I. Evaluation of the method. Br 7 Haematol 1966; 12: 161-6.

8 Corazza GR, Bullen AW, Hall R, Robinson PJ, Losowsky MS Simple method of assessing splenic function in coeliac disease. Clin Sci 1981; 60: 109-13.

9 Foster PN, Losowsky MS. Hyposplenism - a review. $\mathcal{F} R$ Coll Physicians Lond 1987; 21: 188-91.

10 Zieve L. Jaundice, hyperlipemia and hemolytic anemia: a heretofore unrecognised syndrome associated with alcoholic fatty liver and cirrhosis. Ann Int Med 1958; 48: 471-96.

11 Wyke RJ. Problems of bacterial infection in patients with liver disease. Gut 1987; 28: 623-41.

12 Adelstein A, White G. Alcoholism and morbidity. Population Trends 1976; 6: 7-13.

13 Markus HS, Toghill PJ. Impaired splenic function in elderly people. Age Aging 1991; 20: 287-90

4 Holroyde CP, Gardner FH. Acquisition of autophagocytic vacuoles by human erythrocytes: physiological role of the spleen. Blood 1970; 36: 566-75.

15 Spencer RP, Pearson HA. Splenic radiocolloid uptake in the presence of circulating howell-jolly bodies. $\mathcal{F} \mathrm{Nucl}$ Med presence of $15: 294-5$.

16 Zago MA, Covas DT, Figueiredo MJ, Bottura C. Red cell pits appear preferentially in old cells after splenectomy. Acta Haematol (Basel) 1986; 76: 54-6.

17 Wardle EN, Anderson A, James O. Kupffer cell phagocytosis in relation to BSP clearance in liver and inflammatory bowel disease. Dig Dis Sci 1980; 25: 414-9.

18 Lahnborg G, Friman L, Berghem L. Reticuloendothelial function in patients with alcoholic liver cirrhosis. Scand $f$ Gastroenterol 1981; 16: 481-9.

19 Cooksley WGE, Powell LW, Halliday JW. Reticuloendothelial phagocytic function in human liver disease and its relation to haemolysis. Br f Haematol 1973; 25: 147-64.

20 Zoli G, Corazza GR, Wood S, Farthing MJG. Impaired splenic function in patients with intestinal failure on long term intravenous nutrition. Gut 1993; 34: S33. 